\title{
PENGARUH KUALITAS PRODUK DAN HARGA TERHADAP KEPUTUSAN PEMBELIAN KAYU PADA CV. HARAPAN JAYA III KASEMEN KOTA SERANG
}

\author{
Ega Maulidya', Surti Zahra', Amah Suhamah \\ ${ }^{1,2,3}$ Universitas Bina Bangsa \\ zahra3803@gmail.com,
}

\begin{abstract}
ABSTRAK
Penelitian ini bertujuan untuk mengetahui pengaruh Kualitas Produk dan Harga terhadap Keputusan Pembelian Kayu pada CV. Harapan Jaya III Kasemen Kota Serang. Jenis penelitian ini menggunakan pendekatan kuantitatif dengan metode asosiatif. Populasi dalam penelitian ini sebanyak 70 orang adalah konsumen Kayu CV. Harapan Jaya III. Teknik pengambilan sampel menggunakan Probability sampling adalah teknik untuk memberikan peluang yang sama pada setiap anggota populasi untuk dipilih menjadi anggota sampel yaitu sebanyak 70 responden. Hasil penelitian menunjukan bahwa secara parsial Kualitas Produk berpengaruh positif terhadap Keputusan Pembelian. Kemudian Harga berpengaruh positif terhadap keputusan pembelian dan Sedangkan secara bersama-sama Kualitas Produk dan Harga berpengaruh terhadap Keputusan Pembelian. Hasil penelitian menyimpulkan bahwa secara parsial Kualitas Produk berpengaruh terhadap Keputusan Pembelian dan Harga berpengaruh terhadap Keputusan Pembelian. Sedangkan secara simultan Kualitas Produk dan Harga berpengaruh terhadap Keputusan Pembelian.
\end{abstract}

Kata Kunci : Kualitas Produk, Harga, Keputusan Pembelian

\section{ABSTRACT}

For the price of wood sold at CV. Harapan Jaya III is a little more expensive compared to other wood products. This study aims to determine the effect of Product Quality and Price on Wood Purchase Decisions at CV. Harapan Jaya III Kasmen Kota Serang. This type of research uses a quantitative approach with associative methods. The population in this study as many as 70 people are consumers of Wood CV. Harapan Jaya III. The sampling technique using probability sampling is a technique to provide equal opportunities for each member of the population to be selected as a member of the sample, which is as many as 70 respondents. The results showed that partially product quality had a positive effect on purchasing decisions. Then the price has a positive effect on purchasing decisions and simultaneously product quality and price affect purchasing decisions. The results of the study conclude that partially product quality affects purchasing decisions and prices affect purchasing decisions. Meanwhile, product quality and price simultaneously affect the purchase decision.

Keywords: Product Quality, Price, Purchase Decision.

\section{PENDAHULUAN}

Persaingan bisnis yang semakin ketat saat ini menuntut perusahaan untuk semakin gencar dalam pemasarannya untuk menarik dan mempertahankan konsumennya. Hal ini membuat perusahaan harus semakin kreatif dalam menjalankan kegiatan usahanya. Berbagai upaya dilakukan oleh perusahaan untuk meningkatkan penjualan perusahaan serta memuaskan kebutuhan pelanggannya. Menyadari hal itu, jelas bahwa pemasaran merupakan salah satu kegiatan pokok yang dilakukan oleh perusahaan untuk mempertahankan kelangsungan hidupnya untuk berkembang dan mendapatkan laba, serta memperkuat posisi dalam 
Prosiding The 1st National Conference on Applied Business, Education, \& Technology (NCABET)"

Unversitas Bina Bangsa 2021

DOI Article : 10.46306/ncabet.v1i1.49

menghadapi perusahaan pesaing. Strategi bisnis yang tepat dalam perusahaan akan berdampak sangat besar pada kesuksesan perusahaan dalam menjalankan prosedur kinerja yang sesuai dengan target yang akan dicapai.

Menurut Kotler (2016) Keputusan pembelian merupakan hal yang utama dalam aktivitas manajemen pemasaran karena produk atau jasa yang dijual terpengaruh oleh keputusan yang diambil oleh konsumen. Keputusan tersebut tentu berdasarkan pertimbangan yang dipikirkan oleh konsumen. Uraian tersebut sesuai dengan definisi keputusan pembelian adalah keputusan untuk membeli produk yang paling disukai konsumen berdasarkan pertimbangan diantara merek-merek pilihan. Artinya konsumen memegang penuh kendali didalam keputusan pembelian suatu produk atau jasa yang dijual oleh penyedia produk atau jasa tersebut. Terkadang ada beberapa konsumen yang sudah memesan dan kemudian kayu siap untuk dikirim ke lokasi konsumen tiba-tiba konsumen membatalkan secara sepihak dari konsumen, sehingga membuat perusahaan mengalami sedikit kerugian tapi jika banyak konsumen yang melakukan pembatalan pesanan maka perusahaan akan mengalami kerugian cukup besar.

Selain keputusan pembelian faktor penting lainnya dalam aktivitas pemasaran adalah kualitas produk. Menurut Wibowo (2015) Kualitas produk adalah segala sesuatu yang ditawarkan kepada pangsa pasar agar diperhatikan, diminta, dipakai atau dikonsumsi sehingga memuaskan kebutuhan manusia. Jadi kualitas produk disuatu perusahaan memiliki sifat yang harus memiliki keunggulan di mata konsumen agar dapat menarik perhatian konsumen. Untuk masalah kualitas produk CV. Harapan Jaya III terkadang ketika membeli kayu dari produsen dalam bentuk bongkahan terdapat kayu yang kurang bagus. Hal ini membuat produsen komplen akan kayu yang dibeli seperti ada beberapa kayunya hitam di bagian dalamnya ataupun kayu itu saat di potong berbagai ukuran mudah patah yang kurangnya ketelitian saat membeli kayu dari pemasok. Kemudian dari ukuran kayu dan perhitungan dalam bentuk kubik yang kurang tepat dalam perhitungannya yang tidak teliti dari pegawai.

Setiap barang yang diperjual belikan pasti memiliki harga. Harga tersebut digunakan untuk menaksir nilai uang dari suatu produk atau jasa. Menurut Cannon (2016) Harga adalah sesuatu yang harus diberikan oleh pelanggan untuk mendapatkan keunggulan yang ditawarkan oleh bauran pemasaran perusahaan, jadi harga memainkan peran langsung dalam membentuk nilai pelanggan. Maka dari itu harga memiliki posisi penting dalam transaksi jual beli produk atau jasa. Untuk harga kayu yang dijual pada CV. Harapan Jaya III tergolong sedikit lebih mahal di bandingkan dengan produk kayu toko lain. Kemudian harga yang sudah diterterakan pada CV. Harapan Jaya III ini tidak bisa melakukan tawar menawar. Selain itu untuk harga jual 
Prosiding The 1st National Conference on Applied Business, Education, \& Technology (NCABET)"

Unversitas Bina Bangsa 2021

DOI Article : 10.46306/ncabet.v1i1.49

kayu ini terkadang mengalami penurunan dan kenaikan harga jual dikarenakan tergantung banyak atau tidak bahan baku yang di produksikan karena di masa pandemi ini banyak pabrikpabrik disuruh tutup kemudian bahan baku yang masuk dari produsen tidak sampai ke perusahaan dikarenakan ada penutupan jalan sehingga membuat perusahaan CV. Harapan Jaya III mengalami kesulitan dalam memperoleh bahan baku untuk di produksi.

\section{Pengertian Keputusan Pembelian}

Menurut Kotler dan Amstrong (2016) Keputusan pembelian adalah Consumer behavior is the study of how individual, groups, and organizations select, buy, use, and dispose of goods, services, ideas, or experiences to satisfy their needs and wants. yang artinya Keputusan pembelian merupakan bagian dari perilaku konsumen ,perilaku konsumen yaitu studi tentang bagaimana individu, kelompok, dan organisasi memilih, membeli, menggunakan, dan bagaimana barang, jasa, ide atau pengalaman untuk memuaskan kebutuhan dan keinginan mereka.

Menurut Fandy (2014) Keputusan pembelian adalah sebuah proses dimana konsumen mengenal masalahnya, mencari informasi mengenai produk atau merek tertentu dan mengevaluasi seberapa baik masing-masing alternatif tersebut dapat memecahkan masalahnya, yang kemudian mengarah kepada keputusan pembelian.

Menurut Kotler (2016) Keputusan pembelian adalah keputusan untuk membeli produk yang paling disukai konsumen berdasarkan pertimbangan diantara merek-merek pilihan.

Menurut Kotler dan Keller (2016) Keputusan pembelian adalah suatu proses yang berasal dari semua pengalaman mereka dalam pembelajaran, memilih, menggunakan dan bahkan menyingkirkan suatu produk.

Menurut Peter dalam Cristy (2017) Keputusan pembelian adalah proses integrasi yang digunakan untuk mengkombinasikan pengetahuan untuk mengefaluasi dua atau lebih perilaku alternative dan memilih satu di antaranya.

\section{Indikator Keputusan Pembelian}

Adapun Indikator Keputusan Pembelian menurut Swastha (2015) :

1. Memilih produk

Pemilihan suatu produk sangat erat kaitannya dengan kebutuhan yang dimiliki oleh konsumen, artinya untuk konsumen yang rasional dengan budget berbatas akan

\section{Pilihan merek}

Konsumen harus mengambil keputusan tentang merek nama yang akan dibeli setiap merek memiliki perbedaan tersendiri. Dalam hal ini perusahaan harus mengetahui bagaimana konsumen memilih sebuah merek. 
3. Pilihan penyalur

Konsumen harus mengambil keputusan tentang penyalur mana yang akan dikunjungi. Setiap konsumen berbeda-beda dalam hal menentukan penyalur bisa dikarenakan faktor lokasi yang dekat, harga yang murah, persediaan barang yang lengkap, kenyamanan dalam belanja, keluasan tempat dan lain-lain.

4. Waktu pembelian

Keputusan konsumen dalam pemilihan waktu pembelian bisa berbeda-beda misalnya ada yang membeli setiap hari, satu minggu sekali, dua minggu sekali dan lain sebagainya.

5. Jumlah pembelian

Konsumen dapat mengambil keputusan tentang seberapa banyak produk yang akan dibelanjakan pada suatu saat. Pembelian yang dilakukan mungkin lebih dari satu. Dalam hal ini perusahaan harus mempersiapkan banyaknya produk sesuai dengan keinginan yang berbeda-beda.

6. Metode pembayaran

Konsumen dapat mengambil keputusan tentang metode pembayaran yang akan dilakukan dalam pengambilan keputusan menggunakan produk atau jasa. Saat ini keputusan pembelian dipengaruhi oleh tidak hanya oleh aspek lingkungan dan keluarga, keputusan pembelian juga dipengaruhi oleh teknologi yang digunakan dalam transaksi pembelian.

\section{Pengertian Kualitas Produk}

Menurut Wibowo (2015) Kualitas produk adalah segala sesuatu yang ditawarkan kepada pangsa pasar agar diperhatikan, diminta, dipakai atau dikonsumsi sehingga memuaskan kebutuhan manusia. Menurut Miguna dan Nurhafifah (2020) Kualitas produk adalah suatu kondisi dimana sebuah barang bernilai sesuai barang dengan standar ukur yang telah ditetapkan. Menurut Tjiptono (2015) Kualitas produk adalah segala sesuatu yang dapat ditawarkan produsen untuk diperhatikan, diminta, dicari, dibeli, digunakan, dan dikonsumsi pasar sebagai pemenuhan atau keinginan pasar yang bersangkutan. Menurut Kotler dan Kevin (2016) Kualitas produk adalah keahlian suatu produk untuk memberikan hasil atau kinerja yang sesuai bahkan melebihi dari apa yang diinginkan pelanggan. Menurut Schiffman dan Kanuk (2017) Kualitas produk adalah kemampuan suatu perusahaan untuk memberikan identitas atau ciri pada setiap produknya sehingga konsumen dapat mengenali produk.

\section{Indikator Kualitas Produk}


Prosiding The 1st National Conference on Applied Business, Education, \& Technology (NCABET)"

Unversitas Bina Bangsa 2021

DOI Article : 10.46306/ncabet.v1i1.49

1. Performance (kinerja)

Merupakan elemen kualitas produk yang berkaitan langsung dengan bagaimana suatu produk dapat menjalankan fungsinya untuk memenuhi kebutuhan konsumen.

2. Reliabilitas (keandalan)

Merupakan daya tahan produk selama dikonsumsi.

3. Feature (fitur)

Merupakan fungsi-fungsi sekunder yang ditambahkan pada suatu produk.

4. Durability (daya tahan)

Menunjukkan suatu pengukuran terhadap siklus produk, baik secara teknis maupun waktu.

\section{Konsisten}

Menunjukkan seberapa jauh suatu produk dapat memenuhi standar atau spesifikasi tertentu.

6. Desain

Merupakan aspek emosional dalam memengaruhi kepuasan konsumen sehingga desain kemasan ataupun bentuk produk akan turut mempengaruhi persepsi kualitas produk tersebut. (Sopiah dan Etta, 2016).

Pengertian Harga

Menurut Kotler dan Amstrong (2018) Harga adalah sejumlah uang yang ditukarkan untuk sebuah produk atau jasa. Lebih jauh lagi, harga adalah sejumlah nilai yang konsumen tukarkan untuk sejumlah manfaat dengan memiliki atau menggunakan suatu barang atau jasa.

Menurut Tjiptono (2018) Harga adalah satuan moneter atau ukuran lainnya (termasuk barang dan jasa) yang ditukar agar memperoleh hak kepemilikan atau penggunaan suatu barang atau jasa.

Menurut Kotler dan Susanto (2016) Harga adalah satuan moneter atau ukuran lainnya (termasuk jasa atau barang) yang ditukarkan agar memperoleh hak kepemilikan atau penggunaan suatu barang atau jasa.

Menurut Hurryati (2016) Harga memiliki peran penting dalam proses pengambilan keputusan yaitu peranan alokasi dari harga adalah membantu para pembeli untuk memutuskan cara memperoleh manfaat atau utilitas tertinggi yang diharapkan berdasarkan kekuatan daya belinya. Menurut Dwi, dkk (2017) Harga adalah jumlah uang “ditambah beberapa barang jika memungkinkan" yang dibutuhkan untuk mendapatkan sejumlah kombinasi dari barang beserta pelayanannya. 
Prosiding The 1st National Conference on Applied Business, Education, \& Technology (NCABET)"

Unversitas Bina Bangsa 2021

DOI Article : 10.46306/ncabet.v1i1.49

Menurut Achmad (2017) Harga adalah nilai pertukaran atas manfaat produk (bagi konsumen maupun produsen) yang umumnya dinyatakan salam satuan moneter (rupiah, dollar, yen, DM, peso, rupe, france dan lain-lain) harga (price) merupakan jumlah uang yang dibebankan dikarenakan atas sebuah produk/jasa. Harga menurut produsen sebagai nilai barang yang mampu memberikan manfaat pencapaian, tujuan organisasi, memperoleh laba, mengatasi persaingan, dan lain-lain. Sedangkan bagi konsumen memandang harga sebagai nilai barang yang mampu memberikan manfaat atas pemenuhan kebutuhan dan keinginan.

\section{Indikator Harga}

Indikator harga menurut Kotler dan Amstrong (2012) yang bisa digunakan dalam penelitian ini antara lain:

1. Katerjangkauan harga

Harga yang terjangkau adalah harapan konsumen sebelum mereka melakukan pembelian. Konsumen akan mencari produkproduk yang harganya dapat mereka jangkau.

2. Kesesuaian harga dengan kualitas produk

Untuk produk tertentu, biasanya konsumen tidak keberatan apabila harus membeli dengan harga relative mahal asalkan kualitas produknya baik. Namun, konsumen lebih menginginkan produk dengan harga murah dan kualitas baik.

3. Daya saing harga

Perusahaan menetapkan harga jual suatu produk dengan mempertimbangkan harga produk yang dijual oleh pesaingnya agar produknya dapat bersaing di pasar.

4. Kesesuaian harga dengan manfaat

Tinggi rendahnya harga harus sesuai dengan manfaat yang diterima oleh konsumen setelah melakukan pembelian.

\section{METODE PENELITIAN}

Metode Penelitian pada dasarnya merupakan cara ilmiah untuk mendapatkan data dengan tujuan dan kegunaan tertentu. Adapun metode yang digunakan penulis dalam penelitian adalah metode kuantitatif. Menurut Sugiyono (2017) Metode kuantitatif merupakan metode penelitian yang berlandaskan pada filsafat positivisme, digunakan untuk meneliti pada populasi atau sampel tertentu, pengumpulan data menggunakan instrumen penelitian, analisis data bersifat kuantitaif/statistik, dengan tujuan untuk menguji hipotesis yang ditetapakan. Penelitian ini menggunakan metode survey dengan pendekatan kuantitatif, pendekatan yang dimaksud 
Prosiding The 1st National Conference on Applied Business, Education, \& Technology (NCABET)"

Unversitas Bina Bangsa 2021

DOI Article : 10.46306/ncabet.v1i1.49

adalah menjelaskan hubungan kausal dan hipotesis. Jenis penelitian survei ini memfokuskan pada pengungkapan hubungan kausal antar variable.

Populasi dalam penelitian ini adalah orang yang melakukan pembelian produk kayu pada CV. Harapan Jaya III Kasemen Kota Serang dengan jumlah populasi diambil dari tanggal 15 bulan April sampai dengan tanggal 30 bulan Mei sebanyak 70 orang.

Dalam pengambilan sampel ini penulis menggunakan sampel jenuh adalah teknik penentuan sampel bila semua anggota populasi digunakan sebagai sampel, sehingga sampel yang penulis ambil dalam penelitian ini adalah konsumen pada CV. Harapan Jaya III Kasemen Kota Serang 70 sampel.

\section{HASIL DAN PEMBAHASAN}

\section{Uji Regresi Linier Berganda}

Analisis ini dimaksudkan untuk mengetahui pengaruh variabel Kualitas Produk dan Harga terhadap Kepuasan Konsumen. Dan hasil pengolahan data dengan bantuan software SPSS Versi 26 dapat dilihat pada tabel 1 sebagai berikut :

Tabel 1 Hasil Analisis Linier Berganda

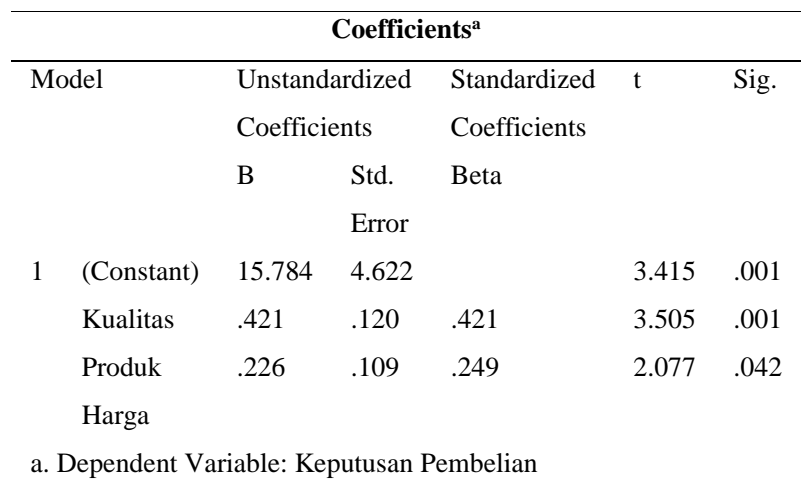

Dependent Variable : Keputusan Pembelian

Dari hasil pengolahan di atas dengan bantuan software SPSS Versi 26 disusun persamaan sebagai berikut :

$\mathrm{Y}=15.784+0.421 \mathrm{X} 1+0.226 \mathrm{X} 2$

Y : Keputusan pembelian

X1 : Kualitas produk

X2 : Harga

A : Bilangan konstanta

Interpretasi Persamaan Regresi

1. Jika kualitas produk nol dan harga nol maka keputusan pembelian sebesar 15.784 satuan. 
Prosiding The 1st National Conference on Applied Business, Education, \& Technology (NCABET)"

Unversitas Bina Bangsa 2021

DOI Article : 10.46306/ncabet.v1i1.49

2. Jika kualitas produk naik satu satuan maka keputusan pembelian naik 0.421 satuan maka harga di anggap tetap

3. Jika harga naik satu satuan maka keputusan pembelian naik sebesar 0.226 satuan, maka kualitas produk dianggap tetap.

\section{Uji Signifikansi Parameter Secara Parsial (Uji T)}

Uji t dikenal dengan uji parsial, yaitu untuk menguji bagaimana pengaruh masing-masing variabel bebasnya secara sendiri-sendiri terhadap variabel terikatnya. Untuk menguji apakah hipotesis yang ditetapkan semula diterima atau ditolak, maka dilakukan perbandingan nilai $\mathrm{t}$ hitung dengan t tabel. Dalam uji ini peneliti menggunakan bantuan software SPSS Versi 26. Untuk mengetahui nilai dengan kriteria pengujian sebagai berikut :

- $\quad$ Jika $t_{\text {hitung }}>t_{\text {tabel }}$, maka Ho ditolak dan Ha diterima.

- $\quad$ Jika $t_{\text {hitung }}<\mathrm{t}_{\text {tabel}}$, maka Ho diterima dan Ha ditolak.

Berdasarkan analisis uji T (parsial) dengan software SPSS Versi 26, berikut ini adalah hasil perhitungan yang ditampilkan pada tabel 1.2 sebagai berikut :

Tabel 2 Uji T Kualitas Produk (X1) dan Harga (X2)

\begin{tabular}{|c|c|c|c|c|c|c|}
\hline \multicolumn{7}{|c|}{ Coefficients $^{\mathrm{a}}$} \\
\hline \multicolumn{2}{|c|}{ Model } & \multirow{2}{*}{\multicolumn{2}{|c|}{$\begin{array}{l}\text { Unstandardized } \\
\text { Coefficients }\end{array}$}} & \multirow{4}{*}{$\begin{array}{l}\text { Standardized } \\
\text { Coefficients } \\
\text { Beta }\end{array}$} & \multirow[t]{4}{*}{$\mathrm{T}$} & \multirow[t]{4}{*}{ Sig. } \\
\hline & & & & & & \\
\hline & & \multirow[t]{2}{*}{$\mathrm{B}$} & Std. & & & \\
\hline & & & Error & & & \\
\hline \multirow[t]{4}{*}{1} & (Constant) & 15.784 & 4.622 & & 3.415 & .001 \\
\hline & Kualitas & .421 & .120 & .421 & 3.505 & .001 \\
\hline & Produk & .226 & .109 & .249 & 2.077 & .042 \\
\hline & \multicolumn{6}{|l|}{ Harga } \\
\hline & ependent V & iable: $\mathrm{Ke}$ & outusan & embelian & & \\
\hline
\end{tabular}

Berdasarkan hasil analisis regresi diperoleh nilai thitung. Nilai yang dihasilkan dari uji hipotesis untuk $t_{\text {hitung }}$ kualitas produk sebesar 3.505. Diketahui nilai $t_{\text {tabel }}$ sebesar 1,99547, karena nilai $t_{\text {hitung }}$ lebih besar dari $\mathrm{t}_{\text {tabel }}\left(\mathrm{t}_{\text {hitung }} 3.505>\mathrm{t}_{\text {tabel }}\right.$ 1,99547), Ho ditolak dan Ha diterima. Hal ini membuktikan bahwa Kualitas Produk berpengaruh terhadap Keputusan Pembelian.

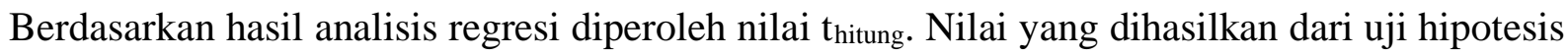
untuk $t_{\text {hitung }}$ harga sebesar 2.077. Diketahui nilai $t_{\text {tabel }}$ sebesar 1,99547, karena nilai $t_{\text {hitung }}$ lebih besar dari $t_{\text {tabel }}\left(t_{\text {hitung }} 2.077>t_{\text {tabel }}\right.$ 1,99547), maka Ho ditolak dan Ha diterima. Hal ini membuktikan bahwa Harga berpengaruh terhadap Keputusan Pembelian.

\section{Uji Signifikansi Parameter Secara Simultan (Uji F)}


Pengujian ini dimaksudkan untuk mengetahui apakah variabel independent secara bersama (simultan) berpengaruh signifikan terhadap variabel dependent. Untuk mengetahui apakah variabel Kualitas Produk (X1) dan Harga (X2) secara bersama-sama (simultan) berpengaruh signifikan terhadap Keputusan Pembelian (Y), maka dilakukan uji F yaitu dengan membandingkan nilai $f_{\text {hitung }}$ dengan $f_{\text {tabel }}$. Berikut ini adalah kriteria pengujian dalam uji $F$ :

a. Jika $f_{\text {hitung }}>\mathrm{f}_{\text {tabel}}$, maka Ho ditolak dan Ha diterima

b. Jika $\mathrm{f}_{\text {hitung }}<\mathrm{f}_{\text {tabel, }}$ maka Ho diterima dan Ha ditolak

Berdasarkan analisis uji F (dimultan) dengan software SPSS Versi 26, berikut ini adalah hasil perhitungan yang ditampilkan pada tabel 1.3 sebagai berikut:

Tabel 3 Output Uji F (Simultan)

\begin{tabular}{lllllll}
\hline \multicolumn{7}{c}{ ANOVA $^{\mathrm{a}}$} \\
\hline Model & Sum of Squares & Df & Mean Square & F & Sig. \\
1 & Regression & 305.996 & 2 & 152.998 & 18.902 & $.000^{\mathrm{b}}$ \\
& Residual & 542.304 & 67 & 8.094 & & \\
\multicolumn{2}{c}{ Total } & 848.300 & 69 & & \\
a. Dependent Variable: Keputusan Pembelian & & \\
b. Predictors: (Constant), Harga, Kualitas Produk
\end{tabular}

Dengan tingkat keyakinan sebesar 5\% atau 0,05 dengan derajat kebebasan (df) $\mathrm{N}-\mathrm{K}=$ 70-3 = 67 diketahui nilai $\mathrm{f}_{\text {tabel }}$ sebesar 3.13 dari hasil perhitngan didapat nilai $\mathrm{f}_{\text {hitung }} 18.902$, untuk menentukan adakah pengaruhnya atau tidak maka dilakukan perbandingan nilai $\mathrm{f}_{\text {hitung }}=18.902$ $>\mathrm{f}_{\text {tabel }}$ 3.13. berdasarkan kriteria uji di atas dan hasil perhitungan, dapat disimpulkan bahwa secara bersama-sama Kualitas Produk dan Harga mempunyai pengaruh terhadap Keputusan Pembelian.

\section{KESIMPULAN DAN SARAN}

Berdasarkan haasil penelitian dan pembahasan, dapat disimpulkan bahwa pengaruh Kualitas Produk dan Harga terhadap Keputusan Pembelian pada CV. Harapan Jaya III Kasemen Kota Serang adalah sebagai berikut :

1. Kualitas produk berpengaruh terhadap keputusan pembelian kayu pada CV. Harapan Jaya III Kasemen Kota Serang.

2. Harga berpengaruh terhadap keputusan pembelian kayu pada CV. Harapan Jaya III Kasemen Kota Serang.

3. Secara bersama-sama kualitas produk dan harga berpangaruh terhadap keputusan pembelian kayu pada CV. Harapan Jaya III Kasemen Kota Serang.

\section{UCAPAN TERIMA KASIH}


Prosiding The 1st National Conference on Applied Business, Education, \& Technology (NCABET)"

Unversitas Bina Bangsa 2021

DOI Article : 10.46306/ncabet.v1i1.49

Kami ucapkan terima kasih kepad Tim Panitia NCBET yang telah menginisiasi acara serta terima kasih kepada Bpk. Dr. Furtasan Ali Yusuf selaku Rektor UNIBA yang telah mendorong kami untuk selalu aktif dalam melakukan inovasi dan mendorong untuk selalu kreatif dalam melakukan riset yang berkualitas.

\section{DAFTAR PUSTAKA}

Alma, Buchari. (2017), Manajemen Pemasaran dan Pemasaran Jasa, Edisi Revisi, Bandung: Alfabeta

Basu, Swastha. (2015), Azas-Azas Marketing. Yogyakarta:Liberty.

Cannon. (2016). Pemasaran Jasa. Jilid 2. Bogor : PT. Granmedia.

Hurriyati R. (2016), Bauran Pemasaran dan Loyalitas Konsumen. Bandung: Alfabeta.

Lupiyoadi, R. (2016). Manajemen Pemasaran Jasa Berbasis Kompetensi. Salemba Empat.

Kotler, P. (2016), Manajemen Pemasaran. Jakarta:PT. Prenhallinde.

____., dan Keller, K. (2016). Marketing Management (15th Ed.). London: Pearson Education Limited.

____., dan Armstrong, G. (2018), Principles of marketing (17thed.). New Jersey: Pearson Prentince Hall.

____., dan A.B Susanto. (2016), Manajemen Pemasaran di Indonesia. Jakarta: Salemba Empat.

_____., dan Gary Armstrong. (2012), Prinsip-Prinsip Pemasaran. Edisi 13. Jilid 1. Jakarta:Erlangga.

_____., dan Kevin Lane Keller. (2016), Marketing Manajement. $15^{\text {th }}$ Edition New Jersy : Pearson Pretice Hall.

Miguna, Astuti., dan Nurhafifah Matondang. (2020), Manajemen Pemasaran (UMKM dan Digital Sosiall Media).

Yogyakarta: CV. Budi Utama.

Schiffman., dan Kanuk.. (2017), Perilaku Konsumen. Edisi Kedua. Jakarta: PT. Indeks Gramedia.

Sopiah., dan Etta Mamang Sangadji. (2016), Kepenjualan. Jakarta: Bumi Aksara.

Sugiyono. (2017), Metode Kuantitatif, Kualitatifdan R\&D. Alfabeta: Bandung.

Suhartanto, Dwi., Tjetjep Djatnika., dan Ni Nyoman Triyuni. (2017), Ritel Pengelolahan dan Pemasaran, Alfabeta :

Bandung.

Tjiptono, Fandy. (2015), Manajemen Jasa. Jakarta: Banyumedia.

. (2016). Manajemen Pemasaran dan Pemasaran Jasa. Bandung : Alfabeta.

______ (2019), Strategi Pemasaran. Edisi keempat. Yogyakarta: Andi.

-___(2014), Pemasaran Jasa - Prinsip, Penerapan, dan Penelitian. : Yogyakarta : Andi Offset

Wibowo. (2015), Manajemen Kinerja, Edisi Keempat. Jakarta : PT. Rajagrafindo Persada.

\section{JURNAL}

Cristy Jaclin Gerung., Jantje Spang, Sjendry Loindong, 2017, Pengaruh Kualitas Produk, Harga dan Promosi Terhadap Keputusan Pembelian MobilNisan x-train pada PT. Wahana Wirawan Manado, Jumal EMBA Vol. 5, No. 2 . 
Prosiding The 1st National Conference on Applied Business, Education, \& Technology (NCABET)"

Unversitas Bina Bangsa 2021

DOI Article : 10.46306/ncabet.v1i1.49

Friani Gloria Igir., Jhony R. E. Tampi., Henny Taroreh, 2018, Pengaruh Kualitas Produk Dan Harga Terhadap Keputusan Pembelian Mobil Daihatsu Grand Max Pick Up (Studi pada PT. Astra International Tbk Daihatsu Cabang Malalayang), Jurnal Administrasi Bisnis Vol. 6No. 2.

Irfan Rizqullah Ariella, 2018, Pengaruh Kualitas Produk, Harga Produk dan Desain Produk Terhadap Kepuusan Pembelian Konsumen Mazelnid, PERFORMA : Jumal Manajemen dan Start-Up Bisnis Volume 3, Nomor 2, Universitas Ciputra.

Rifqi Sulthan Fahrezzy., Arlin Ferlina Moch.Trenggana, 2018, Pengaruh Kualitas Produk dan Harga Terhadap Keputusan Pembelian Konsumen Laptop Asus, Jumal Indonesia Membangun, Vol. 17, No. 2, Universitas Telkom.

Sari Ismayana., Nur Hayati, 2018, Pengaruh Kualitas Produk dan Harga Terhadap Kepuusan Pembelian Produk Lipstik Pixy (Studi Pada Konsumen ProdukLipstikPixy Toserba Borma Cipadung), Jurnal Sains Manajemen \& Akuntansi, Volume XNo. 2, STIE-STAN IM. 